\title{
Risk and performance management: are they easy partners?
}

Marika Arena and Michela Arnaboldi

Dipartimento di Ingegneria Gestionale, Politecnico di Milano, Milano, Italy

Corresponding author

Marika Arena can be contacted at: marika.arena@polimi.it

\section{Introduction}

Over the last decade, enterprise risk management (ERM) has emerged as a significant tool for transforming risk management from a peripheral technical instrument into a company-wide and integrated process (Mikes, 2009; Power, 2007; Woods, 2009; Arena et al., 2011). This trend has emerged since the early 2000s, yet it gained wider diffusion in 2004 when the Committee of Sponsoring Organisations of the Treadway Commission (COSO, 2004) formally defined a reference framework, introduced as follows:

Enterprise Risk Management is a process, effected by an entity's board of directors, management and other personnel, applied in strategy setting and across the enterprise, designed to identify potential events that may affect the entity, and manage risks to be within its risk appetite, to provide reasonable assurance regarding the achievement of the entity's objectives.

The COSO framework emphasizes the potential of ERM to enhance performance management by relating risk management to organisational objectives (Woods, 2008; Power, 2009). These indications were followed by a number of practitioners who attempted to demonstrate the value-enhancing role of ERM for achieving better corporate performances (Sobel and Reding, 2004; Beasley et al., 2006; Lam, 2006). 
Also the consulting and advisory industries have actively accentuated the link between ERM and performance management, presenting them as two related and synergic processes (Ernst \& Young, 2005; PWC, 2009; McKinsey, 2010), as emerges from the following quote:

Enterprise risk management and enterprise performance management are really two sides of the same coin. To achieve balance between the two, companies must fully integrate risk management with their operating model, performance goal and decision making frameworks (www.accenture.com).

The nature and the goals of performance management show similarities and connections to those of risk management (Collier and Berry, 2002; Ferreira and Otley, 2009; Ojiako, 2012), as highlighted by the following definition of performance management systems (PMS):

[...] the formal and informal mechanisms, processes, systems, and networks used by organizations for conveying the key objectives and goals elicited by management, for assisting the strategic process and on-going management through analysis, planning, measurement, control, rewarding, and broadly managing performance, and for supporting and facilitating organizational learning and change (Ferreira and Otley, 2009, p. 264).

However, whether and how these similarities can be formalized and translated into managerial practices is not clear and, so far, only few academic contributions have explicitly addressed the relationship between PMS and risk management systems (RMS), leading to the objective of this paper. In order to enhance knowledge about the relationship between PMS and RMS, this paper aims to identify some common traits and parallels between them, in terms of scope of the system, measurement and ownership based on a general review of the state of the art literature. This analysis will provide the theoretical foundation to identify and discuss different possible "relational configurations" between the two systems, with potential implications from a managerial and academic perspective.

To achieve this objective, we proceed as follows. We first discuss how recent literature addressed the relationship between PMS and RMS. Then, we present how the literature review was carried out and we introduce the key dimensions along which it was articulated. In Section 4, we present the results of the literature review. In Section 5 , we discuss the implication of our work from a theoretical and managerial perspective and we conclude in Section 6.

\section{Risk and performance management: towards integration?}

As we mentioned in the introduction, the practitioner literature has put forth the view of a natural convergence of RMS and PMS towards integration, with supposedly beneficial consequences for managerial and governance processes. Managerial "talks" suggest that integration has a potentially positive effect on the achievement of corporate objectives, helping organisations to continuously monitor risks and achievements against strategy (PWC, 2009; Paladino, 2008; Ow, 2008). According to practitioners' literature, an integrated risk and PMS could focus managerial attention on "key" data with possible beneficial consequences in terms of decision-making quality (e.g. quicker and more precise responses to external strains) and it could also help in increasing stakeholders' confidence. 
On the other hand, recent academic research seems to be less enthusiastic about the integration of PMS and RMS, and provides evidence of a more complex and heterogeneous situation, highlighting how these systems can (or can not) be interconnected in different ways, depending on a plurality of contingent factors and organizational drivers (Mikes, 2009; Arena et al., 2010; Woods, 2009). Mikes (2009) presented field-based evidence from two large banking organizations, pinpointing the existence of systemic variations in ERM practices and in how ERM is related (or not) to PMS. In particular, in one of the two cases, she highlighted "a considerable level of integration" between strategic planning and risk management functions. "Integration" is driven by a strong "calculative idealism" that led the bank to focus on quantifiable risks and dismiss strategic risks outside the remit of quantified risk management frameworks. Arena et al. (2010) investigated the organizational dynamics of ERM, looking at three companies that have implemented ERM approaches. In their work, the authors illustrated how a "new hybrid ERM/budget style" emerged in a non-financial company operating in Italy and they claimed that this new "style" is contingent to the pivotal role played by the accounting function in orchestrating ERM efforts. Finally, Woods' study of a large UK retailer (Woods, 2009) suggested that, against the backdrop of an explicit strategy of customer value creation, risk management can be implicitly linked to performance management.

These works provide some preliminary insights about the relationship between RMS and PMS, but they do not provide a systemic analysis of different possible connections between the two systems, leading to the focus of this paper. Henceforth, without the intention to analyse in depth the two systems, we examine the key elements that characterize RMS and PMS in order to highlight the existence of some "points of contacts", useful to explain their link.

\section{Methodology}

To map possible points of contact between RMS and PMS we performed a scoping literature review (Arksey and O’Malley, 2005). We selected this approach because considered particularly suitable when the review is aimed to map the current state of the art in an area of interest, that cannot be closely defined, and identify gaps where further research is required. The scoping review may be contrasted with the systematic review, because the latter is more restricted in focus: the systematic review aims to provide answers to questions from a relatively narrow range of quality assessed studies, whilst a scoping study is less likely to seek to address very specific research questions nor to assess the quality of included studies (Arksey and O'Malley, 2005).

To guide the review, we first identified a set of elements that could be used to characterize both RMS and PMS. The literature provides many different frameworks and models that have been used for analyzing either RMS or PMS (Ferreira and Otley, 2009; Simons, 1995). However, since the aim of the review is to map potential points of contact between PMS and RMS, we decided to refer to a general framework, that could be easily applied to both the systems, in order to capture their "core common elements". In particular, we looked at RMS and PMS as socio-technical systems (Trist et al., 1963; Appelbaum, 1997), that can be characterized by technical and social components: scope/goals, technologies and actors/ownership. The scope/goal of the system refers to the focus of RMS and PMS in terms of "decisional areas" that are supported by these instruments. The second element, technologies, refers to the approaches, tools and indicators used to evaluate and quantify performances and risks. 
Finally, the third element, actors/ownership, refers to the actors that manage the systems and that own responsibility of them.

Then, the scoping review was performed following the protocol suggested by Arksey and O'Malley (2005), that consists of five steps:

(1) identifying the questions;

(2) identifying relevant literature;

(3) selecting the literature;

(4) charting the data; and

(5) collating, summarizing and reporting the results (Table I).

\section{Results}

\subsection{Scope}

Through the years, PMS and RMS underwent a significant evolution, that brought to a gradual enlargement of their scope, i.e. the focus in terms of "decisional areas" that are supported by these instruments.

PMS has evolved through four different phases: productivity management, budgetary control, integrated performance measurement and inter-organization performance management (Bititci et al., 2011). In the first phase, between the 1920s and the 1950s, PMS was focused on a limited decisional area - production - with specific attention devoted to cost/efficiency matters (Bititci et al., 2011). In the second phase, between the 1950s and the 1960s, its scope was extended to divisional and departmental budgets, due to the emergence of multiple production plants, with increasing organizational and managerial complexity (Otley, 2003; Bititci et al., 2011). Later, between the 1960s and 1980s, the scope of PMS was further enlarged, integrating new dimensions of performance, such as quality, time, flexibility and customer satisfaction (Hayes and Abernathy, 1980; Slack, 1983; Kaplan, 1984), and leading to the development of more integrated and "balanced" approaches (Johnson and Kaplan, 1987).

Steps of the scoping review

Identifying questions

Identifying relevant literature

Selecting the literature

Charting the data

Collating, summarizing and reporting the results
How the step was performed

The key questions we attempted to answer are: how scope/goals, technologies and actors/ownership of RMS and PMS evolved through the years?

We adopted a strategy that involved searching for research evidence via different sources: electronic databases, hand-searching of key journals, existing networks, relevant organisations and conferences We included papers that could contribute to provide an overall picture of the evolution of RMS and PMS in terms of scope/goals, technologies and actors/ ownership. A preliminary selection was based on the title and abstract of the papers

Materials collected was charted according to the proposed dimensions (scope/goals, technologies and actors/ownership) and mapped in a timeline

The results of the review are presented in section four according to the three dimensions of analysis
Table I. The scoping review 
At this time, the PMS literature started to elaborate the idea of strategic control, making clear the existence of a link between performance indicators and company's strategy, whereby the indicators should be seen as strategic drivers (Horovitz, 1979; Goold and Quinn, 1990; Simons, 1995; Agasisti et al., 2008; Agostino and Arnaboldi, 2012; Lamberti and Noci, 2010). Finally, in the fourth phase, the PMS evolution signaled the need to move beyond the company boundaries, integrating inter-organizational performances and accounting for the impact on a larger set of stakeholders (Marchand and Raymond, 2008; Bititci et al., 2011). On the one hand, to respond to the change of the competitive context (Lehtinen and Ahola, 2010), many organizations have moved towards inter-organizational collaboration and "servitization", configuring themselves as networks (Berry et al., 2009; Bititci et al., 2011; Marques et al., 2011; Arnaboldi and Spiller, 2011). On the other hand, environmental and social results have assumed a growing importance to both legitimate a company's activity and improve its economic performance (Arena et al., 2009; Clemens and Bakstran, 2010; Lamberti and Noci, 2012). This trend has lead to the integration of indicators pertaining to environmental and social performances into the corporate reporting (Adams and Frost, 2008; Arena and Azzone, 2010).

In a similar way, RMS evolved, gradually broadening its scope, through three main phases. The origins of RMS can be traced back to the insurance buying functions, when risk management primarily decisional area was protecting company's assets, by defining a proper insurance coverage. Since the 1960s, risk management principles started to be applied to different types of risk including health and safety risk, environmental risk, financial and market risk (Lave, 1987; Dowd, 1999), with the aim to properly manage these types of risks, not only through insurance - i.e. transferring risk to third parties, but introducing corrective actions to reduce their probability and impacts. Despite this enlargement, at that time, risk management was conceived as a technical activity and performed through a "silo" approach - i.e. individual risk categories were tackled separately: risks were identified, classified and managed with reference to different sub-parts of the organization using local classifications of risks (Close, 1974). Finally, in the last decade, with the introduction of the ERM framework, RMS has assumed a more strategic role (ICAEW, 1999; DeLoach, 2004; Gates, 2006; Olson and $\mathrm{Wu}, 2007)$. ERM is centered on the idea of risk management as a strategic process that addresses all events, which could prevent the achievement of the corporate objectives, in a holistic and integrated way (COSO, 2004). This change of perspective signed the move of RMS from peripheral functional areas of the organization to the corporate level (Arena et al., 2010).

Based on the above analysis, it is clear that PMS and RMS have evolved separately but with relevant similarities. In particular, they are both conceived as control systems, part of a wider accountability framework and the way they enlarged their scope has in common a shift from a technical orientation to a more strategic one in order to better support managers in decision-making activities and contribute to value creation.

\subsection{Measurement}

The second dimension of analysis refers to how performance and risk are measured, encompassing approaches, tools and indicators used to quantify performances and risks. Again the development of PMS and RMS shows significant similarities.

PMS relies on a wide set of indicators that are used to measure performances. At a general extent, we can distinguish between financial indicators, non-financial indicators 
and a balanced set of indicators. Financial indicators are measures expressed by money, which may be calculated on accrual or cash basis. They include traditional ratio indicators, such as ROI and ROE (Arditti, 1967) and newer absolute indicators, such as economic value added and residual income (Young, 1997). These indicators are widely used and have as a main reference financial statements. Yet financial indicators are characterized by shortcomings that are generally related to the possibility of improving their values in the short term, simply by cutting investments, and the lack of a direct link with the specific strategy of a company (Neely, 1999; Norreklit, 2000; Johnston and Pongatichat, 2008; Berry et al., 2009).

Non-financial indicators instead, refer to measures which are not expressed by money. These indicators are aimed at monitoring companies' long-term success factors such as customer satisfaction, efficiency, human resources, innovation. The idea at the basis of these instruments is to forestall the financial impact, implementing a system of "early warnings". Non-financial indicators, if properly designed, detect weak signals (Arena and Arnaboldi, 2012), from both the external environment and internal processes, and provide a more timely view of the business. Providing decision makers information to put forward their actions with a strategic view, they counterbalance some of the limitations characterizing financial indicators (Lynch and Cross, 1991; Ittner and Larcker, 1998; Hoque and James, 2000). Anyhow, their acceptance is not unanimous, since some scholars have pointed out that they are loosely coupled systems lacking of integration with the firm's strategy (Norreklit, 2000; Pun and White, 2005). An attempt to solve this problem is represented by the introduction of integrated performance measurement systems, such as key performance indicators, balanced scorecards and tableau du board, that rely on the idea of providing an integral view of company's performances, supported by financial and non-financial indicators, related to the company's strategy (Pun and White, 2005; Otley, 2008). The selection of the indicators is meant to be driven by the critical success factors of the company that in turn are related to the strategy. The literature points out that a mix of financial and non-financial measures provides a broader understanding of the performance information and contribute to the achievement of strategic objectives (Lee and Yang, 2011). More recent developments highlight the introduction of sustainability and network indicators in this type of integrated performance measurement tools (Figge et al., 2002; Bagwat and Sharma, 2007).

Moving to RMS, we can distinguish different approaches to risk measurement. In particular, risks can be evaluated through qualitative or quantitative techniques or with a combination of the two. Qualitative techniques generally consist in the evaluation of risk probability and impact through the use of Likert scales. They are useful where risks cannot be quantified or when sufficient credible data, required for quantitative evaluation, are not practicably available or not cost-effective (Arena et al., 2011). Quantitative techniques instead consist in quantitative evaluations, that can be based either on financial quantification or on quantitative non-financial measures (such as the computation of the accident rate in safety, estimation of system failures in ICT).

With the rise of ERM systems, further techniques were put forth, with the aim of performing cross-functional evaluations of risk. In particular, three main approaches have gained diffusion (Scandizzo, 2005; Gates, 2006): qualitative evaluations based on risk matrixes, financial evaluation based on indicators such as value at risk (VaR) and capital at risk (CaR); key risk indicators (KRI) and risk scorecards. The risk matrix maps risks pertaining to different functions in a Cartesian graph along two axis: 
probability and impact. Hence, this representation allows to visualize the exposure of the whole enterprise and highlights different areas (quadrants), where risk is ranked high, medium or low, focusing decision makers attention on key risks.

Financial evaluation relies on quantitative risk indicators based on cash flows estimations. Among the most common financial indicators, there are $\mathrm{VaR}$ and $\mathrm{CaR}$, etc. (Jorion, 2000; Holton, 2003). VaR indicates the maximum monetary loss that a company might face during a determined time period. The method is based on a statistical confidence and for that reason requires determining a target confidence level (Jorion, 2000). CaR, instead, is a sort of capital reserve in equity. It is defined as the difference between the mean of the profit-loss distribution of a portfolio and the VaR (Emmer et al., 2001). These measures have rapidly been adopted by financial companies, under the influence of sector regulations (Basel II); an increasing number of non-financial firms are also adopting them, though, recently, these approaches have come under much criticism. In particular, their ability of giving an appropriate risk measure has been questioned, and they have been criticized for being subject to significant estimation errors (Dowd and Blake, 2006; Woods et al., 2008).

In the last years, these indicators have been partly replaced by different tools, that try to better capture the relationships of risk with the business strategy (Williams and Thompson, 2004; Cox, 2008). More specifically their proponents aimed at providing the "right information" to managers, developing indicators which capture potential future risks with a strategic view. These metrics have been labeled KRI (Scandizzo, 2005; Lam, 2006; Beasley et al., 2010). As follows, we report an example taken from Beasley et al. (2010), related to the oversight of account receivables to better understand what a KRI is and compare it against KPIs. A KPI for customer credit is frequently customer write-offs. This indicator provides insights about a risk event that has already occurred (e.g. a customer failed to pay in accordance with the contract). A KRI could be developed to help anticipate potential future customer collection issues so that the credit function could be more proactive in addressing customer payment trends before risk events occur. In this case, a KRI could be a solvency indicator based on an analysis of reported financial results of the company's 25 largest customers, or an average collection indicator computed at the industry level (Beasley et al., 2010).

Based on the above considerations, some commonalities between PMS and RMS emerge, in particular in relationship to the development and use of KRIs. The idea at the basis of the KRI is indeed quite similar to the basic principle of the KPI: they aim to identify measures that allow to understand the evolution of business internal and external drivers. The COSO argues that the main difference between the KRIs and the KPIs is that the latter do not provide adequate early warning indicator of potential risks because they are based mainly on historical data, while the KRIs are oriented to be leading indicators (Beasley et al., 2010). However, at least to some extent, these measures are partially overlapping.

\subsection{Ownership}

The third dimension of analysis is the ownership of the systems. PMS and RMS have been historically associated to different responsibilities that, however, are starting to show some points of contact.

With the exception of the initial phase in which PMS was embedded in the production realm, hence up to production managers, PMS has been traditionally a responsibility of 
management accountants; however, their role has changed significantly in relationship to the PMS evolution. Originally, management accountants had a more financial orientation, being mainly up to the collection and analysis of financial data. This role was in the past often referred to as "number cruncher" or "bean counter" (Byrne and Pierce, 2007; Baldvinsdottir et al., 2009), to underline the strong involvement of management accountant in book-keeping activities. The extension of the scope of PMS to more strategic issues signed a major change in management accountants role. On the one hand, they moved towards a "business partner" role, that implied an active involvement of the accountants in the strategic and operational decision making processes of organisations (Simons, 1995; Siegel and Sorersen, 1999; Gibson, 2002). On the other hand, the enlargement of PMS focus, open up to the possibility for other professionals to increase their ownership in the PMS: management accountants were told in danger of being marginalised (Clarke et al., 1999), with their roles potentially being performed by other professionals, such as operation managers and ICT managers (Cooper, 1996; Pierce, 2001).

Moving to RMS, the ownership of the process should be read in relationship to the two dimensions previously analysed: the evolution of the risk management process and the measurement issue. The evolution of RMS from "silo" to ERM determined the need to have a new position responsible for RMS (Aabo et al., 2005; Gordon et al., 2009). In fact, in the case of "silo" approach, different risk categories were managed by local, separate operational units, responsible for segmental risks, with limited interaction with other parts of the organization (Cumming and Hirtle, 2001; Liebenberg and Hoyt, 2003). ERM, on the contrary, is based on an integrated process, which engages people and systems across the organization and therefore requires higher coordination (Liebenberg and Hoyt, 2003; Gates, 2006; Fraser and Henry, 2007). This responsibility is up to a coordinator/facilitator, often labeled chief risk officer (CRO), which is not necessarily a risk expert, since the CRO acts as a sort of advisor supporting managers in dealing with risks (Aabo et al., 2005). Actually, there is no consensus on the organizational function or professional actor that is most suited to take on this role (Liebenberg and Hoyt, 2003). Among possible actors there are: risk management experts, internal auditors and management accountants, hence leading to a further element of contact between PMS and RMS.

On the other hand, the measurement issue determined a further change in relationship to RMS ownership, this time leading to a higher fragmentation of the actors involved. The literature shows a trend to include new risk experts, which some call "gatekeepers of risk", in order to realize the risk calculations (Mu et al., 2008; Moerman and van der Laan, 2012). In fact, for the implementation of VaR and CaR a specific expertise is required, and even for KRI, it is recommended to count with experts to identify the root causes of risky events (Beasley et al., 2010).

Based on the above considerations, we can highlight some points of contact between RMS and PMS. First, management accountants, the traditional owners of the PMS, are trying to play a more active role in relationship to RMS and there are a few cases in which management accountants have become responsible for risk management coordination (Collier et al., 2007). In addition, the management accounting associations (IMA and CIMA) have started initiatives to drive accountants to increase their role in orchestrating ERM (Pollara, 2008). Second, even when management accountants are not formally responsible for ERM, proper mechanisms of coordination can be developed in order to ensure proper flows of information between the two functions (Arena et al., 2011). 


\section{Discussion}

The previous sections highlighted how RMS and PMS have progressively increased their importance within organizations, expanding their areas of impact, measurement tools and their owners' domain. In this expansion, RMS and PMS have shown several points of contacts and overlapping, which are here discussed in terms of implications on the decision making process. Both RMS and PMS support decision making process at different stages: planning, results analysis and reporting.

Specifically, we articulate the discussion of implications analyzing two polar types of relational configurations between RMS and PMS: disconnected and integrated.

\section{Disconnected configuration}

In the disconnected configuration RMS and PMS are owned, managed and operated in a distinct way. During the planning phase, the two processes collect and simulate data separately with potentially negative impacts on effectiveness and efficiency. First, managers may be asked to provide similar information (risks, forecasts) twice, with loss of time and possible disaffection on this tool. Second, the link between risks and performance is not explicit, leaving managers a joint evaluation, without creating a collective, formal moment in which all these variables are analyzed in relationship to the company's future value. A similar situation affects the analysis of results, where RMS and PMS owners elaborate actual data disjointedly. Considering PMS, variances in performance are not related to causes previously discussed within the RMS: causes are not specified or local analyses are performed. Regarding RMS, the lack of links to performance may create around risk processes an "aura" of compliance: analysis and update are seen as unavoidable task for external accountability (Power, 2007). Finally, a separate reporting means two different processes for preparing the reports targeted at different organizational levels and overload of information received by the same managers. Again the impact is on the efficiency, in terms of used resources, and on the effectiveness: an integrated consideration of risk and performance is left to the single manager attitude and sensitivity.

Summarizing the disconnected approach is less efficient in terms of data collation and it does not create collective managerial arenas (meeting, boards, etc.) in which risk and performance are related to each other. Managers are not supported by integrated measures or tools leaving greater space to their will of jointly analyzing and using data. On the other hand, this situation has some benefits, because it does not imply a re-design of measurement processes and ownerships in a company. Further to the resource saving, the lack of joint measures and ownership leaves the responsibility of integration to managers leaving them higher flexibility and autonomy.

\section{Integrated configuration}

The ideal configuration of integration implies a complete synergy between RMS and PMS, with an integrated ownership or an open equal collaboration; a shared knowledge management of decisional supported areas (scope) and a joint elaboration and use of measurement techniques.

During planning, this situation allows to enhance decision-makers information by simulating jointly expected performance, expected variations (impact and likelihood), punctuated events (risk and opportunities) to trace the causes of change. This situation leads managers to analyse different scenarios not in general terms but identifying 
specific future, risky events, interconnections and the impact on value creation. Beside the most tangible output - integrated plans, this approach helps managers to think in advance to action plans that may be, in some cases, formalized, as already happens for particular risk categories (e.g. crisis management).

The integrated planning sets the basis for designing a complete set of indicators to control and analyze results: KRI to control critical events; non-financial performance indicators to trace actual results anticipating financial impacts; financial indicators to directly monitor variances with expected values or risk exposures. All these information are, in this ideal-type, owned and reported in synergy, providing integrated risk and performance reports at different level of the organizations.

Yet this integrated configuration has also some threats. The most evident is the higher amount of resources needed to set up and maintain an integrated system. The few empirical works available has evidenced that the overall integration of RMS and PMS is left to managers, while in this configuration owners design and operate integrated measures or visual instruments in planning, measurement and reporting. The second issue is related: shifting the synthesis of information from managers to PMS and RMS owners gives to these figures a higher responsibility, entailing high-level of technical but also organizational competences.

\section{Conclusions}

The potential links between RMS and PMS have attracted a significant attention in recent years, with the emergence of the ERM framework. However, the academic literature is still poor of contributions specifically addressing the relationship between PMS and RMS. In this context, our paper aimed at analyzing the points of contact between the two systems, through a general literature review. This examination pinpointed how PMS and RMS present relevant similarities and potential synergies that, at present, are only partially exploited, and highlighted how the two systems could be connected through managerial instruments and organizational arrangements. This analysis provides managers with useful insights on pros and cons of integrating RMS and PMS and possible modes of doing it.

RMS and PMS are both aimed at supporting decision makers in achieving corporate objectives. On the one hand, PMS translates this aspiration by defining and looking at targets, measuring actual results, supporting learning and actions based on results and their variance from targets. It deals with the plans, activities and processes that an organization adopts to implement its strategic objectives (Otley, 1999). On the other hand, RMS, in the ERM shape, looks at the events that could determine a variation from the achievement of the company's objectives (COSO, 2004). Although starting from companies objectives, risk measurement is more focused on events that can cause variations. Objectives are not measured, as in PMS, but they are implicitly assessed by predicting and measuring their potential loss (probability and impact). Action is meant to be always present in different phases of the risk management process, but large emphasis is put on proactive actions to mitigate risk, before events take place.

Moving from these considerations, we have highlighted the existence of different potential "relational configurations" of the two systems and we have introduced two polar types - the disconnected and the integrated configuration - that represent opposite ways of relation between RMS and PMS, with different impacts on the decision making process. The extent to which these polar types are diffused among companies 
is an open issue, though the general trend shown in the review indicates a heterogeneous situation (Arena et al., 2010; Arnaboldi and Lapsley, 2011). This finding suggests the need for further research in order to analyse possible variations of these polar types i.e. the existing configurations between disconnection and integration - and the actual diffusion of different arrangements. In addition, future research could explore the factors at the basis of the development of a specific configuration and the consequences of the adoption of a specific arrangement: for instance, analysing if and how the evolution of RMS and PMS does impact on the existing relationship between the two, represents a challenging research question. In both cases, our framework (scope, measurement, owners) and related results provide a lens for empirical analysis of configurations and their organisational trajectory.

The future development could sign a relevant contribution to the scant literature that looks at RMS and PMS as two interconnected systems. In addition, a better understanding of this issue could help managers and practitioners in designing their systems more coherently with the purposes for which they want use them. Finally, future research may focus also on professions, analysing empirically the task, role and power of different professionals involved in RMS and PMS. All these researches entail both quantitative and qualitative studies or a combination of the two approaches.

\section{References}

Aabo, T., Fraser, J.R.S. and Simkins, B.J. (2005), "The rise and evolution of the chief risk officer: enterprise risk management at hydro one", Journal of Applied Corporate Finance, Vol. 17 No. 3, pp. 62-75.

Adams, C.A. and Frost, G.R. (2008), "Integrating sustainability reporting into management practices", Accounting Forum, Vol. 32 No. 4, pp. 288-302.

Agasisti, T., Arnaboldi, M. and Azzone, G. (2008), "Strategic management accounting in universities: the Italian experience", Higher Education, Vol. 55 No. 1, pp. 1-15.

Agostino, D. and Arnaboldi, M. (2012), "Design issues in balanced scorecards: the 'what' and 'how' of control”, European Management Journal, Vol. 30 No. 4, pp. 327-339.

Appelbaum, S.H. (1997), "Socio-technical systems theory: an intervention strategy for organizational development”, Management Decision, Vol. 35 No. 6, pp. 452-463.

Arditti,F.(1967), "Risk and the required return on equity",Journal of Finance, Vol. 22 No. 1, pp.19-36.

Arena, M. and Arnaboldi, M. (2012), "Risk and budget in an uncertain world", International Journal of Business Performance Management, Vol. 14 No. 2, pp. 166-180.

Arena, M. and Azzone, G. (2010), "A process-based approach to select key sustainability indicators for steel companies", Ironmaking and Steelmaking: Processes, Products and Applications, Vol. 37 No. 6, pp. 437-444.

Arena, M., Arnaboldi, M. and Azzone, G. (2010), "The organizational dynamics of enterprise risk management", Accounting Organization and Society, Vol. 35 No. 7, pp. 659-675.

Arena, M., Arnaboldi, M. and Azzone, G. (2011), “Is enterprise risk management real?", Journal of Risk Research, Vol. 17 No. 4, pp. 779-797.

Arena, M., Ciceri, N.D., Terzi, S., Bengo, I., Azzone, G. and Garetti, M. (2009), “A state-of-the-art of industrial sustainability: definitions, tools and metrics", International Journal of Product Lifecycle Management, Vol. 4 Nos 1-3, pp. 207-251.

Arksey, H. and O'Malley, L. (2005), "Scoping studies: towards a methodological framework", International Journal of Social Research Methodology, Vol. 8 No. 1, pp. 19-32. 
Arnaboldi, M. and Lapsley, I. (2011), "Enterprise risk management and budgetary control: a management challenge", CIMA Research Executive Summary Series, Vol. 7 No. 6, pp. 1-8.

Arnaboldi, M. and Spiller, N. (2011), "Actor network theory and stakeholder collaboration: the case of cultural districts”, Tourism Management, Vol. 32 No. 3, pp. 641-654.

Bagwat, R. and Sharma, M.K. (2007), "Performance measurement of supply chain management: a balanced scorecard approach", Computers \& Industrial Engineering, Vol. 53 No. 1, pp. 43-62.

Baldvinsdottir, G., Burns, J., Nørreklit, H. and Scapens, R.W. (2009), "The image of accountants: from bean counters to extreme accountants", Accounting, Auditing \& Accountability Journal, Vol. 22 No. 6, pp. 858-882.

Beasley, M., Branson, B.C. and Hancock, B.V. (2010), Developing Key Risk Indicators to Strengthen Enterprise Risk Management, available at: www.coso.org/documents/ COSOKRIPaperFull-FINALforWebPostingDec110_000.pdf (accessed 30 July 2012).

Beasley, M., Chen, A., Nunez, N. and Wright, L. (2006), "Working hand in hand: balanced scorecard and enterprise risk management", Strategic Finance, March, pp. 49-55.

Berry, A.J., Coad, A.F., Harris, E.P., Otley, D.T. and Stringer, C. (2009), "Emerging themes in management control: a review of recent literature", The British Accounting Review, Vol. 41 No. 1, pp. 2-20.

Bititci, U., Garengo, P., Dörfler, V. and Nudurupati, S. (2011), "Performance measurement: challenges for tomorrow", International Journal of Management Reviews, Vol. 14 No. 3, pp. 305-327.

Byrne, S. and Pierce, B. (2007), "Towards a more comprehensive understanding of the roles of management accountants”, European Accounting Review, Vol. 16 No. 3, pp. 469-498.

Clarke, P.J., Hill, N.T. and Stevens, K. (1999), “Activity-based costing in Ireland: barriers to and opportunities for change”, Critical Perspectives on Accounting, Vol. 10 No. 4, pp. 443-468.

Clemens, B. and Bakstran, L. (2010), "A framework of theoretical lenses and strategic purposes to describe relationships among firm environmental strategy, financial performance, and environmental performance”, Management Research Review, Vol. 33 No. 4, pp. 393-405.

Close, D.B. (1974), “An organization behavior approach to risk management”, Journal of Risk and Insurance, Vol. 41 No. 3, pp. 435-450.

Collier, P.M. and Berry, A.J. (2002), "Risk in the process of budgeting", Management Accounting Research, Vol. 13 No. 3, pp. 273-297.

Collier, P.M., Berry, A.J. and Burke, G.T. (2007), Risk and Management Accounting, CIMA, London.

Cooper, R. (1996), "Look out, management accountants", Management Accounting, June, pp. 35-41.

COSO (2004), Enterprise Risk Management Framework, Committee of Sponsoring Organizations of the Treadway Commission, American Institute of Certified Public Accountants, New York, NY.

Cox, L.A. Jr (2008), “What's wrong with risk matrices?”, Risk Analysis, Vol. 28 No. 2, pp. 497-512.

Cumming, C.M. and Hirtle, B.J. (2001), "The challenges of risk management in diversified financial companies", FRBNY Economic Policy Review, March, pp. 1-17.

DeLoach, J. (2004), “The new risk imperative - and enterprise-wide approach", Handbook of Business Strategy, Vol. 5 No. 1, pp. 29-34.

Dowd, K. (1999), "Financial risk management", Financial Analysts Journal, Vol. 55 No. 4, pp. $65-71$. 
Dowd, K. and Blake, D. (2006), "After VaR: the theory, estimation, and insurance applications of quantile-based risk measures”, Journal of Risk and Insurance, Vol. 73 No. 2, pp. 193-229.

Emmer, S., Klüppelberg, C. and Korn, R. (2001), "Optimal portfolios with bounded capital at risk", Mathematical Finance, Vol. 11 No. 2, pp. 365-384.

Ernst \& Young (2005), "Managing risk across the enterprise", available at: www.enrst\&young. com (accessed January 2012).

Ferreira, A. and Otley, D. (2009), "The design and use of performance management systems: an extended framework for analysis", Management Accounting Research, Vol.20 No. 4, pp. 263-282.

Figge, F., Hahn, T., Schaltegger, S. and Wagner, M. (2002), "The sustainability balanced scorecard - linking sustainability management to business strategy", Business Strategy and the Environment, Vol. 11 No. 5, pp. 269-284.

Fraser, I. and Henry, W. (2007), "Embedding risk management: structures and approaches", Managerial Auditing Journal, Vol. 22 No. 4, pp. 392-409.

Gates, S. (2006), "Incorporating strategic risk into enterprise risk management: a survey of current corporate practice", Journal of Applied Corporate Finance, Vol. 18 No. 4, pp. 81-90.

Gibson, D.A. (2002), "On-property hotel financial controllers: a discourse analysis approach to characterizing behavioural roles", International Journal of Hospitality Management, Vol. 21 No. 1, pp. 5-23.

Goold, M. and Quinn, J.J. (1990), “The paradox of strategic controls”, Strategic Management Journal, Vol. 11 No. 1, pp. 43-57.

Gordon, L.A., Loeb, M.P. and Tseng, C. (2009), "Enterprise risk management and firm performance: a contingency perspective", Journal of Accounting \& Public Policy, Vol. 28 No. 4, pp. 301-327.

Hayes, R.H. and Abernathy, W.J. (1980), "Managing our way to economic decline”, Harvard Business Review, Vol. 58, July-August, pp. 67-77.

Holton, G. (2003), Value-at-Risk: Theory and Practice, Academic, San Diego, CA.

Hoque, Z. and James, W. (2000), "Linking balanced scorecard measures to size and market factors", Journal of Management Accounting Research, Vol. 12, pp. 1-17.

Horovitz, J.H. (1979), "Strategic control: a new task for top management”, Long Range Planning, Vol. 12, June, pp. 2-7.

ICAEW (1999), Internal Control - Guidance for Directors on the Combined Code, Turnbull Report, Institute of Chartered Accountants in England and Wales, London.

Ittner, C.D. and Larcker, D.L. (1998), "Innovations in performance measurement, trends and research implications”, Journal of Management Accounting Research, Vol. 10, pp. 205-238.

Johnson, H.T. and Kaplan, R.S. (1987), Relevance Lost - The Rise and Fall of Management Accounting, Harvard Business School Press, Boston, MA.

Johnston, R. and Pongatichat, P. (2008), "Managing the tension between performance measurement and strategy: coping strategies", International Journal of Operations \& Production Management, Vol. 28 No. 10, pp. 941-967.

Jorion, P. (2000), Value at Risk: The New Benchmark for Managing Financial Risk, McGraw-Hill, New York, NY.

Kaplan, R.S. (1984), “The evolution of management accounting”, Accounting Review, Vol. 59, July, pp. 390-418.

Lam, J. (2006), Emerging Best Practices in Developing Key Risk Indicators and ERM Reporting, available at: ftp://service.boulder.ibm.com/software/data/sw-library/cognos/pdfs/ whitepapers/wp_best_pract_in_dev_key_risk_indicators_erm_rep.pdf (accessed 30 July 2012). 
Lamberti, L. and Noci, G. (2010), "Marketing strategy and marketing performance measurement system: exploring the relationship", European Management Journal, Vol.28 No. 2, pp. 139-152.

Lamberti, L. and Noci, G. (2012), "CSR as a strategic lever in medium-sized companies: evidence from Italy”, Business Ethics: A European Review, Vol. 21 No. 4, pp. 402-416.

Lave, L. (1987), "Health and safety risk analyses: information for better decisions", Science, Vol. 236 No. 4799, pp. 291-295.

Lee, C. and Yang, H. (2011), "Organization structure, competition and performance measurement systems and their joint effects on performance", Management Accounting Research, Vol. 22 No. 2, pp. 84-104.

Lehtinen, J. and Ahola, T. (2010), "Is performance measurement suitable for an extended enterprise?", International Journal of Operations \& Production Management, Vol. 30 No. 2, pp. 181-204.

Liebenberg, A. and Hoyt, R.E. (2003), "The determinants of enterprise risk management: evidence from the appointment of chief risk officers", Risk Management \& Insurance Review, Vol. 6 No. 1, pp. 37-52.

Lynch, R.L. and Cross, K.F. (1991), Measure Up! - Yardsticks for Continuous Improvement, Blackwell Publishers, Cambridge, MA.

McKinsey (2010), “A board perspective on enterprise risk management”, McKinsey Working Paper on Risk, Vol. 18, February, pp. 1-15.

Marchand, M. and Raymond, L. (2008), "Researching performance measurement systems an information systems perspective", International Journal of Operations \& Production Management, Vol. 28 No. 7, pp. 663-686.

Marques, L., Ribeiro, J.A. and Scapens, R.W. (2011), "The use of management control mechanisms by public organizations with a network coordination role: a case study in the port industry”, Management Accounting Research, Vol. 22 No. 4, pp. 269-291.

Mikes, A. (2009), "Risk management and calculative cultures", Management Accounting Research, Vol. 20 No. 1, pp. 18-40.

Moerman, L.C. and van der Laan, S.L. (2012), "Risky business: socializing asbestos risk and the hybridization of accounting", Critical Perspectives on Accounting, Vol. 23 No. 2, pp. 107-116.

Mu, J., Peng, G. and MacLachlan, D.L. (2008), "Effect of risk management strategy on NPD performance", Technovation, Vol. 29 No. 3, pp. 170-180.

Neely, A. (1999), "The performance measurement revolution: why now and what next?", International Journal of Operations \& Production Management, Vol. 19 No. 2, pp. 205-228.

Norreklit, H. (2000), "The balance on the balanced scorecard a critical analysis of some of its assumptions", Management Accounting Research, Vol. 11 No. 1, pp. 65-88.

Ojiako, U. (2012), "Examining thematic elements in strategic business risk", Management Research Review, Vol. 35 No. 2, pp. 90-105.

Olson, D. and Wu, D. (2007), Enterprise Risk Management, World Scientific Publishing, Singapore.

Otley, D. (1999), "Performance management: a framework for management control systems research”, Management Accounting Research, Vol. 10 No. 4, pp. 363-382.

Otley, D. (2003), "Management control and performance management: whence and whither?", British Accounting Review, Vol. 35 No. 4, pp. 309-326.

Otley, D. (2008), "Did Kaplan and Johnson get it right?", Accounting, Auditing \& Accountability Journal, Vol. 21 No. 2, pp. 229-239.

Ow, P. (2008), "Outperform by linking risk and performance management", Accountants Today, February, pp. 26-28. 
Paladino, B. (2008), "Strategically managing risk in today's perilous markets", Strategic Finance, November, pp. 27-33.

Pierce, B. (2001), "Management accounting without accountants?", Accountancy Ireland, Vol. 33 No. 3, pp. 10-12.

Pollara, J.B. (2008), "FGRC: seize the opportunity", Strategic Finance, May, pp. 58-59.

Power, M. (2007), Organized Uncertainty: Designing a World of Risk Management, Oxford University Press, Oxford.

Power, M. (2009), “The risk management of nothing”, Accounting, Organizations and Society, Vol. 34 Nos 6/7, pp. 849-855.

Pun, K.F. and White, A.S. (2005), "A performance measurement paradigm for integrating strategy formulation: a review of systems and frameworks", International Journal of Management Reviews, Vol. 7 No. 1, pp. 49-71.

PWC (2009), "Seizing opportunity: linking risk and performance”, available at: www.pwc.com/en US/us/risk-performance/assets/pwc-risk-performance-2009.pdf (accessed 30 June 2012).

Scandizzo, S. (2005), "Risk mapping and key risk indicators in operational risk management", Economic Notes, Vol. 34 No. 2, pp. 231-256.

Siegel, G. and Sorersen, J.E. (1999), Counting More, Counting Less: The 1999 Practice Analysis of Management Accounting, Institute of Management Accountants, Montvale, NJ.

Simons, R. (1995), Levels of Control - How Managers Use Innovative Control Systems to Drive Strategic Renewal, Harvard Business School Press, Boston, MA.

Slack, N. (1983), "Flexibility as a manufacturing objective", International Journal of Operations and Production Management, Vol. 3 No. 3, pp. 4-13.

Sobel, P.J. and Reding, K.F. (2004), "Aligning corporate governance with enterprise risk management”, Management Accounting Quarterly, Vol. 5, Winter, pp. 29-37.

Trist, E.L., Higgin, G.W., Murray, H. and Pollock, A.B. (1963), Organizational Choice, Tavistock Publications, London.

Williams, R.A. and Thompson, K.M. (2004), "Integrated analysis: combining risk and economic assessments while preserving the separation of powers", Risk Analysis, Vol. 24 No. 6, pp. 1613-1623.

Woods, M. (2008), “A commentary on the COSO internal control framework and its links with Sarbanes-Oxley", in Woods, M., Kajüter, P. and Linsley, P. (Eds), International Risk Management, CIMA, London.

Woods, M. (2009), “A contingency theory perspective on the risk management control system within Birmingham city council”, Management Accounting Research, Vol. 20 No. 1, pp. 69-81.

Woods, M., Dowd, K. and Humphrey, C. (2008), "The value of risk reporting: a critical analysis of value-at-risk disclosures in the banking sector", International Journal of Financial Services Management, Vol. 3 No. 1, pp. 45-64.

Young, D. (1997), "Economic value added: a primer for European managers", European Management Journal, Vol. 15 No. 4, pp. 335-343. 